\title{
Article \\ Agent-based Modeling of a Self-Organized Food Safety System
}

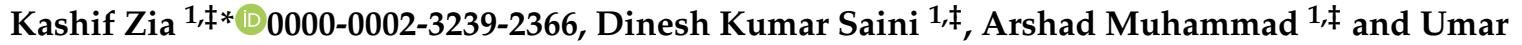 \\ Farooq 2, \\ 1 Faculty of Computing and Information Technology, Sohar University, Sohar, Oman; \\ 2 University of Science and Technology, Bannu, Pakistan; \\ * Correspondence: kzia@soharuni.edu.om; Tel.: +x-xxx-xxx-xxxx \\ $\ddagger$ These authors contributed equally to this work. \\ Academic Editor: name \\ Received: date; Accepted: date; Published: date
}

\begin{abstract}
The wisdom of crowd" is so often observed in social discourses and activities around us. The manifestations of it are, however, so intrinsically embedded and behaviorally accepted that an elaboration of a social phenomenon evidencing such wisdom is often cheered as a discovery; or at least an astonishing fact. One such scenario is explored here, namely conceptualization and modeling of a food safety system, a system directly related to social cognition. Food safety is an area of concern these days. Models representing the food safety systems are recently published to study the effect of interactions between important entities of the system. For example, Knowles's model finds conditions leading to a more efficient and dependable system of entities like consumers, regulators and stores with specific focus on regulators behavior and their impact on the food safety. The first contribution of this paper is reevaluation of Knowles's model towards a more conscious understanding of "the wisdom of crowd" effects on inspection and consuming behaviors. The second contribution is augmenting of the model with social networking capabilities, which acts as a medium to spread information about stores and help consumers find stores which are not contaminated. Simulation results reveal that stores' respecting social cognition improve effectiveness of the food safety system for consumers and stores both. Simulation findings also reveals that an active society has a capability to self-organize effectively even in the absence of any regulatory compulsion.
\end{abstract}

Keywords: Food Safety; Agent-Based Model; Social Networking; Recommendation; the wisdom of crowd.)

\section{Introduction}

Food safety is a growing concern. The population of the world is increasing exponentially. This growth is uneven, where, the population in economically poor countries is growing more rapidly than the economically stable countries. It means that the countries which can spend more on food safety are less vulnerable, and, already have better systems and healthcare facilities. Whereas, countries which have issues in their economics systems and healthcare, are more likely to suffer due to rapid growth in population.

Scientific advancements provide opportunities towards standardized harvesting and logistics procedures, and safeguarding against contamination in stores. But still a lot needs to be done [1]. This is evident from on going concerns in government circles [2,3] and communities [4,5]. At operational level, no doubt, the regulatory authorities of a country have a major role, which should have an effective, and robust mechanism to deal with modalities of food contamination.

Over the past years, the global food distribution and supply chain has become very complex due to an increase in the population in general, and more specifically, due to an increase in farmers, suppliers, traders and consumers. This has led to several food safety crises recently. Due to this, a debate is underway towards many solutions, including, making more strict laws, rethinking about prevalent industrial practices and a fresh approach to understand consumers' behaviors [6]. 
Food supply chain, consumption and quality control is a huge system, constituted by many sub-systems, starting from soil and water (for cultivation of a crop) and ending at healthcare (treatment of diseases from the food). It includes many systems such as agricultural procedures, logistics, warehousing, supply, packing, storage, consumption, healthcare, and quality control procedures. We only focus on a sub-system which can be treated as an independent system; a triangular system of stores connected to consumers and regulators.

Assessment and correction of food contamination is usually done using food inspection programs in which, stores providing food get central attention. However, it is observed that due to lack of standards, the allocation of inspection resources and agreeing on contamination thresholds has become a challenge $[7,8]$. On the other hand, consumers are equally important [8]. The psychological factors representing the perceptions $[9,10]$ and attitudes [11] of consumers about the food quality is as important as food inspections mechanisms.

Most social systems including food delivery and consumption evolve with time, based on society's needs and restrictions. However, most of these systems are far from perfection due to:

- Diversity of human race, which manifests into a heterogeneous population in terms of resources, capabilities, and individualism.

- Inherent lack of balance in human cognition due to selfishness and uneven social and political justice.

- Existence of a gap between social / scientific knowledge and the development of an individual, which practically keeps these systems in a state often not optimized.

- Flaw in human knowledge and judgment.

Computational Social Science (CSS) [12] is a young discipline, which focus on using computations to solve social problems. It uses the power of abstraction and modeling to mimic real systems in a formal way so that computers can understand and process them. Agent-Based Modeling (ABM) [13] is a front-runner modeling technique used in CSS. In ABM, real objects of interest are modeled as agents having a simplified representation of their characteristics, behaviors, and interactions. Many of individual agents then interact (work together) in a sequential time progression transiting from one state to another representing an evolving society.

The problem of food safety has been tackled with ABM [14]. Naturally, the entities of interest can be farms, warehouses, trucks, stores, workers, consumers and regulators, etc. Depending on the problem scale, some entities are relevant and some are not. For example, food safety from a consumer view point can only focus on the landscape in which a consumer is interacting with the food items. Recently, such a simplistic model is presented by Knowles [1]. The model only have three type of agents; consumers, stores and regulators. The purpose of the model is to investigate the effect of information sharing between stores and regulators on the quality of food consumed by the consumer.

This paper also presents an agent-based model of food safety management. The model proposed by [1] involving consumers, regulators and stores is extended to evaluate the phenomena of "the wisdom of crowd" towards the conditions leading to safer and more dependable food system. Knowles considers two information modalities from stores to regulators. First is when a store starts "signaling" on its own if it is contaminated. In this case, a regulator would promptly visit the store to sterilize it. The second is when contaminated store does not signal and regulators' visit are purely random. In both cases, a consumer, if encountering a contaminated store, registers that store in its "bad_stores" list, and never visits it again. This behavior represents an individualistic, self-interested decision rather than the notion of the wisdom of crowd [15]; a decision by a crowd as a whole.

Nevertheless, the wisdom of crowd can be implied by noting consumers not visiting a store anymore. Knowles does not model the effect of consumers not visiting a store in the store's decision. In fact, a store does not make a decision altogether. It goes into a contaminated state randomly unless it is visited by a regulator (by responding to a signaling store or randomly). During this time, a first time visitor would register this store in its bad list once and for all. The store does not have to take 
any action against decreasing number of consumers. We introduce a model to capture this aspect. We categorize stores as "vigilant" and "indifferent", where vigilant stores are responsive to the wisdom of crowd (a commutation of individuals' decision) and take effective and timely means to improve the food quality. To support this mechanism, we have related a store's contamination with the food quality. Also, the quality does not abruptly switches between the extremes (contaminated and sterilized), but improves and degrades progressively (which seems more realistic).

With these enhancements, the model proposed in this paper is able to investigate the effect of vigilance of stores on consumers' health. Our hypothesis is that more vigilant stores - in a situation of decreasing crowd interest due to degradation in the quality of food - would keep a large fraction of consumers - consumers who do not have prior experience with the store-a potential consumer when compared to stores which are indifferent. The consequence of it would be a more fair distribution of consumers across competing stores, thus, improving dependability of the overall system.

In the second phase of the model, we consider, social networking as a mean of disseminating the information about "good_stores". Instead of a store signaling its contamination status, consumers' experience makes it good or bad. This information is private to the consumers and can be shared with their friends. We hypothesize that social networking-based information sharing would improve the consumers' experience as a whole.

In the following, we specify these hypotheses more explicitly:

- Hypothesis 1 (H1): More vigilant crowd, both stores and consumers, would not only improve the quality of food provided and consumed, but also, ensures a fair distribution of consumers across the stores.

- Hypothesis 2 (H2): Social networking-based information sharing would improve the consumers' experience further, consequently rapidly improving the quality of food provided.

The rest of the paper is organized as follows. Section 2 presents the motivation of the proposed model, followed by the proposed model in section 3. In Section 4, the simulation scenarios and analysis of simulation results are presented. The paper ends with conclusions of the study presented in Section 5 .

\section{Motivation}

A general overview of applications of modeling and simulation to solve real life problem is presented by Ipek Bozkurt and Jose J. Padilla [16] focused on Epistemological, Ontological, Teleological and Methodological themes. More related to the our research is the work of Mercedes Bledaa and Simon Shackley [17] using agent-based simulation to study formation of risk perceptions; one of the many social theory driven models which have been simulated [18-21]. Additionally, in systems, many simulation models are proposed i.e., recent model of supply-chain proposed by Houtian Ge, et. al. [22].

An agent-based model simulating an agri-food supply chain is presented in [23]. Another agent-based model to measure the effects of incentive and communication programs towards food safety is proposed by Tim Verwaart and Natalia I. Valeeva [24]. Heterogeneous agents are used representing various modalities of motivations and openness to communications. Jessye Bemley Talley's thesis [25] presents agent-based models to investigate on different aspects of consumer behaviors in the spread of contamination and conditions, in which the public health department must intervene to stop the spread.

Only a few authors have used ABM in the domain of food safety. Knowles's Model of Food Safety Inspections [1] is novel, simple and intriguing. We extend this model to investigate about consumers and store owners, the social dimension. We propose that consumers and owners of the stores accepting existence of "the wisdom of crowd", can make good decision; good for themselves, but at the same time, beneficial for the society as a whole. 


\section{Models}

\subsection{Model of Food Safety Inspections [1]}

The model is based on three agent breeds, (i) consumers, (ii) regulators, and (iii) stores. A consumers executes processes of CONSUME and HEAL, a regulator performs TEST, and a store acts to SPREAD and SIGNAL.

Consume and Heal: A consumer consumes food of a store if she is healthy, while waiting to be healthy again if she is contaminated with the food already taken. For consumption of the food, she chooses a random store in her proximity (defined by her range of accessibility) which is not identified as contaminated by one of the regulators / store or already listed in bad stores from her prior experience. If the chosen store is not contaminated, she lists it as a good store. Otherwise, she is considered as sick if contamination (a random value of plausible health hazard) imposed by the food is more than her immunity, consequently listing the chosen store in the list of bad stores. A consumer also performs healing if it is sick, and her counter of healing is still less than prescribed threshold. Fig. 1 depicts this process.

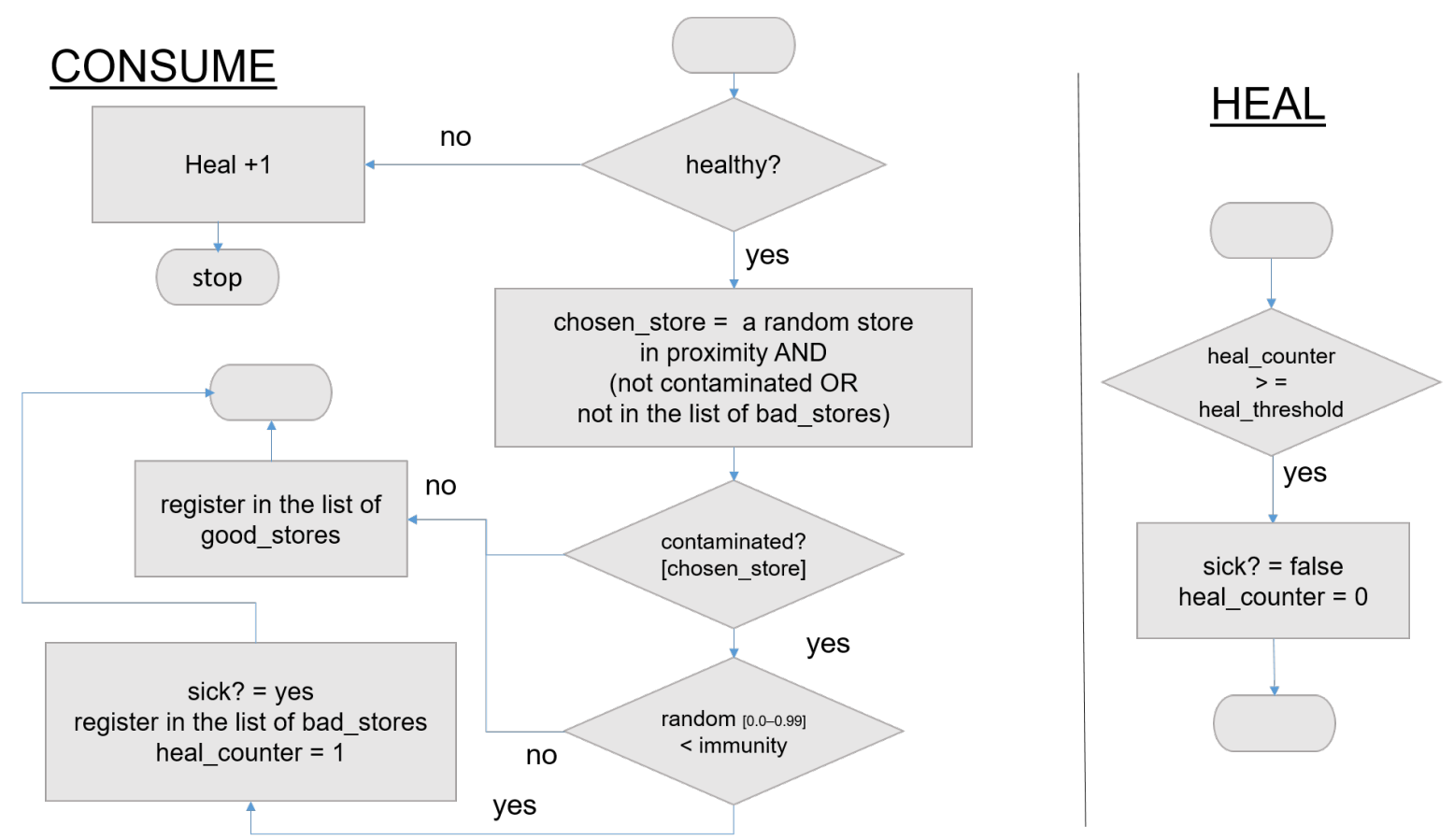

Figure 1. Knowles's Model of Food Safety Inspections. Process of Food Consumption and Healing by Consumers.

Spread and Signal: A store may becomes contaminated at a random instance. It may also decide to signal its state of being contaminated. Fig. 2 depicts this process.

Test: A regulator visits a random store in her proximity (defined by her range of accessibility which is more than consumer's) that is already signaling. If no such store exists, it visits any random store in her proximity. As a result of her visit, the store becomes sterilized. Fig. 3 depicts this process.

Knowles considers two information modalities from stores to regulators. First is when a store starts "signaling" on its own if it is contaminated. In this case, a regulator would promptly visit the store to sterilize it. The second is when contaminated store does not signal and regulators' visit are purely random. Naturally, stores signaling themselves would be the best choice, but its practicality can be debated. We take [1] model as our base case. 


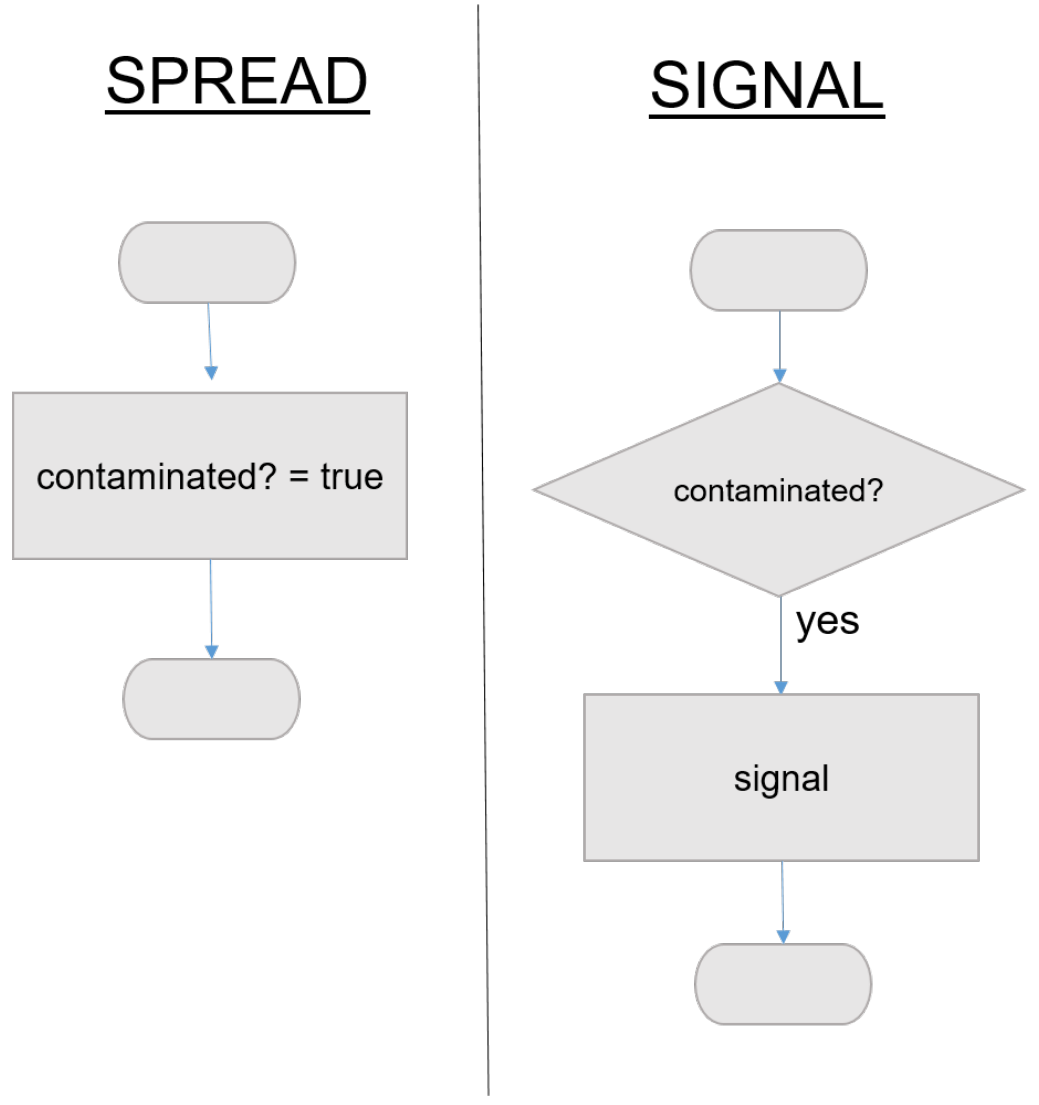

Figure 2. Knowles's Model of Food Safety Inspections. Process of Spreading and Signaling by Stores.

\subsection{The Proposed Model (partially published [26])}

The proposed model does not include signaling process. Also, we add a new process for stores, namely quality UPDATE.

Quality Update: The UPDATE process enables a progressive quality improvement or degradation of food provided by the store. The progression in one direction (improvement or degradation) proceeding for a longer period of time before switching from one direction to the other. Evaluation of the quality of the food is then integrated with other processes as well. Such as, the SPREAD of contamination is no more an unconditional decision. A store becomes 'really' contaminated, if quality of the store is less than quality_threshold (a static value between 0.1 to 0.9). The changes in Knowles's Model are highlighted in Fig. 4 which also have depiction of update process.

Similar changes are implemented in TEST by regulators in which a store's quality needs to be above threshold to take it as sterilized. The changes in Knowles's Model are depicted in Fig. 5.

Further, the UPDATE process further extended, to reflect the effect of crowd (customers at a particular time) at the store. If " $\mathrm{c}$ " is the number of consumers at a store, and the quality of food at the store is less than the threshold, then a "vigilant" store would like to have drastic change in the quality, improving it quantitatively proportional to the crowd (say equivalent to reciprocal of " $\mathrm{c}$ "). These differences are highlighted in Fig. 6.

\subsection{The Proposed Model: Further Extension}

There are two aspects that we considered in the further extension of the model. In the previous model, if a store in the neighborhood of a consumer which is safe (not currently contaminated and in the list of bad stores) was not found, the consumer used to "wander". Wandering is a process of choosing another location randomly in the current tick and start searching for a candidate safe store in 


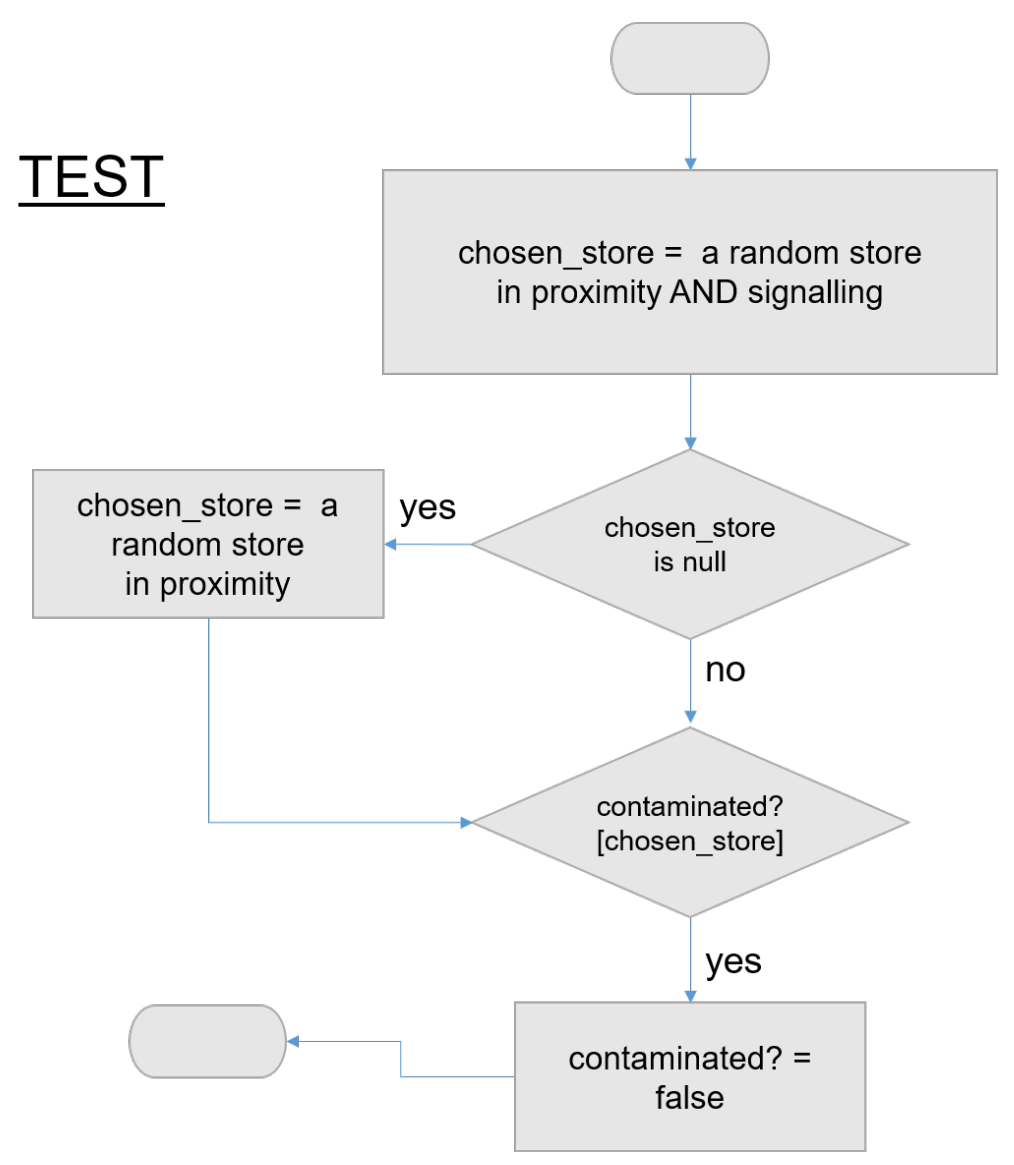

Figure 3. Knowles's Model of Food Safety Inspections. Process of Testing by Regulators.

the next tick. This is counter intuitive, just like considering that a store start signaling as soon as it get contaminated.

The first contribution of this model is then the deletion of wandering process. This will definitely increase the number of consumers who are not able to find a safe store. Now the question is that how we can compensate this loss.

Social Networking: We propose to use a social network model to achieve it. Agents perform calculations and act in a sequence; the order of the sequence randomly shuffled for each iteration. A network between agents is at the setup time. All agents form links with the other agents as described in the following.

Let "friends" is a 2D array or table data structure of an agent, which contains all of its friends, according to the following:

- total connections depends on connectivity index (the percentage of people connected to each other)

- many connections are local which depends on local connections index

- quite a few connections are remote; the remaining connections

Figure 7 shows a sample setup in which blue connections are local and red connections are remote. It means that many consumers are having friends now, which is a static connectivity happening at the simulation startup and remains till the end of a simulation run. Some friends are in local (in the proximity of initial placement of a consumers), while the remaining are distant. The connectivity with the friends makes a consumer take recommendations from one of his friends instead of wandering (in case no store is available).

To support social networking data management and possible recommendations, now a consumer also registers a good store in a list called "green_stores"; stores which she has visited herself and 


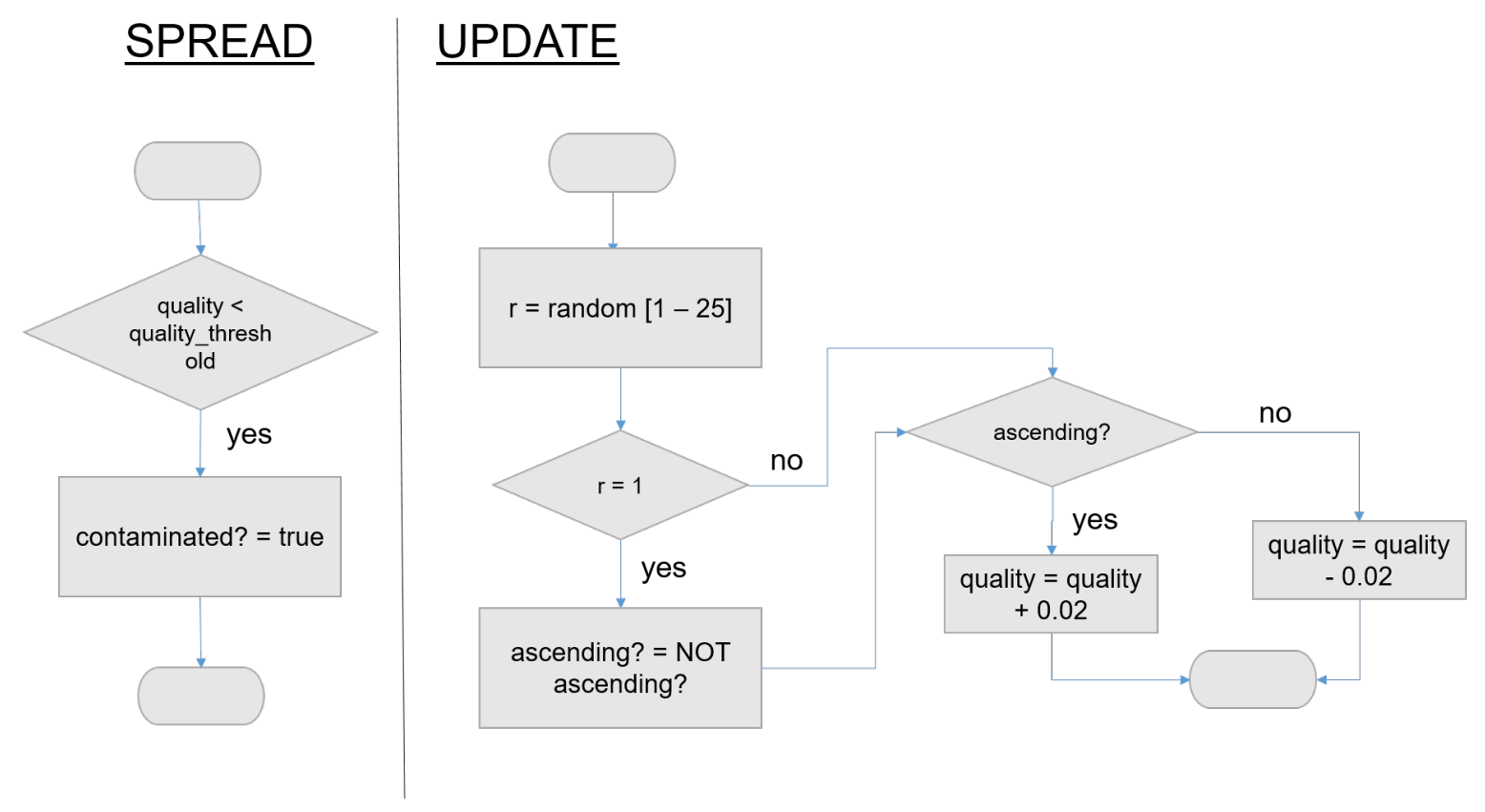

Figure 4. Proposed model of Food Safety Inspections. Process of Spreading and Quality Update by Stores.

\section{$\underline{\text { TEST }}$}

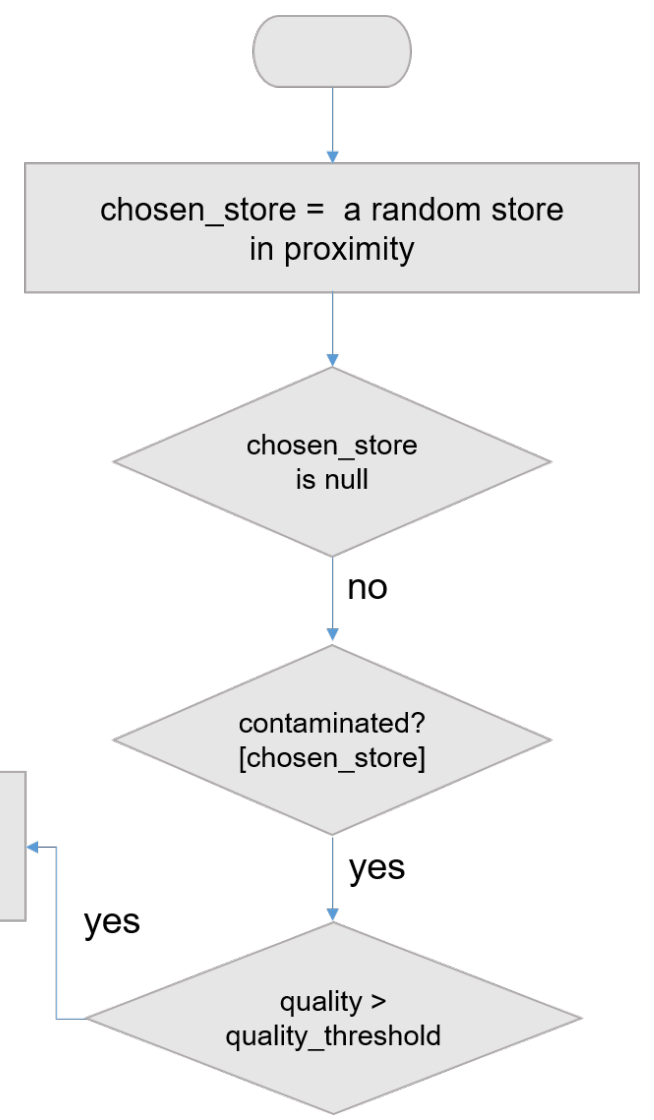

Figure 5. Proposed model of Food Safety Inspections. Process of Testing by Regulators.

found healthy. Now, if during the choosing process, the chosen store is null (not store found in the 


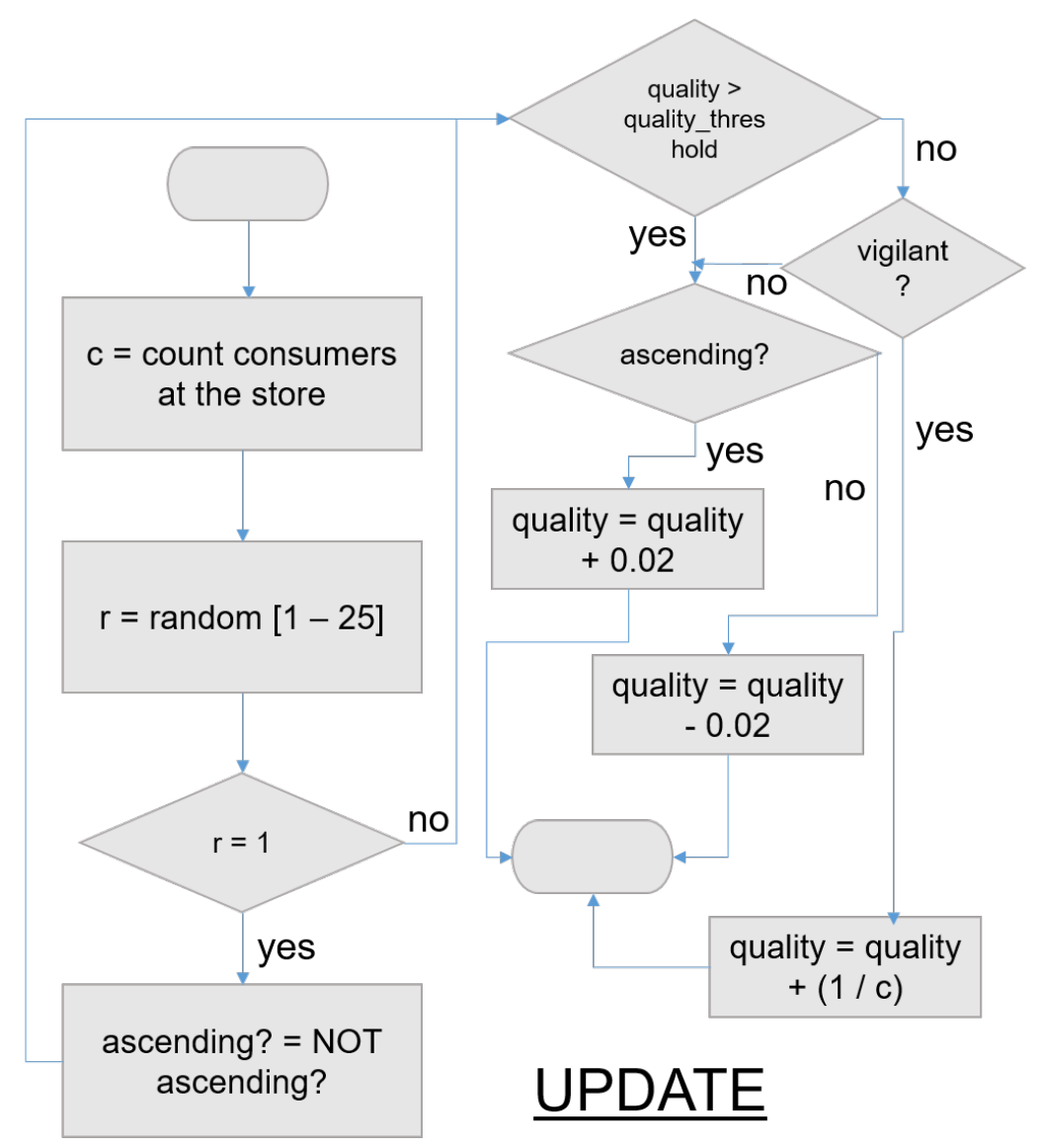

Figure 6. Proposed model of Food Safety Inspections. Quality Update Process. Further Extension.

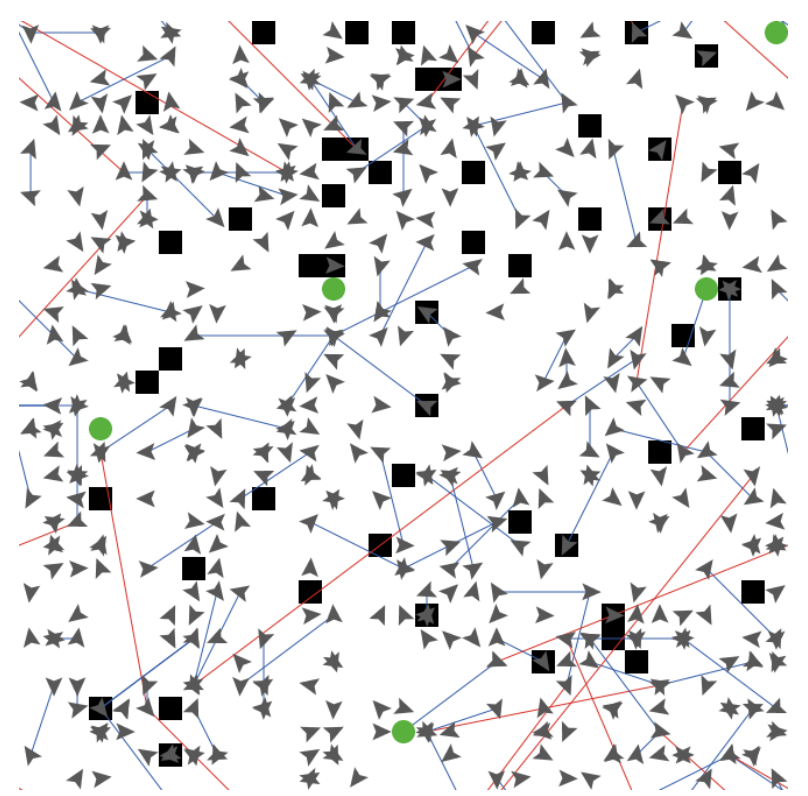

Figure 7. A sample connectivity setup in which the blue connections are local and the red connections are remote.

proximity), she would ask a randomly chosen friend of her to provide a random store from the list of "green_stores". The new consume process is proposed and shown in Figure 8. 


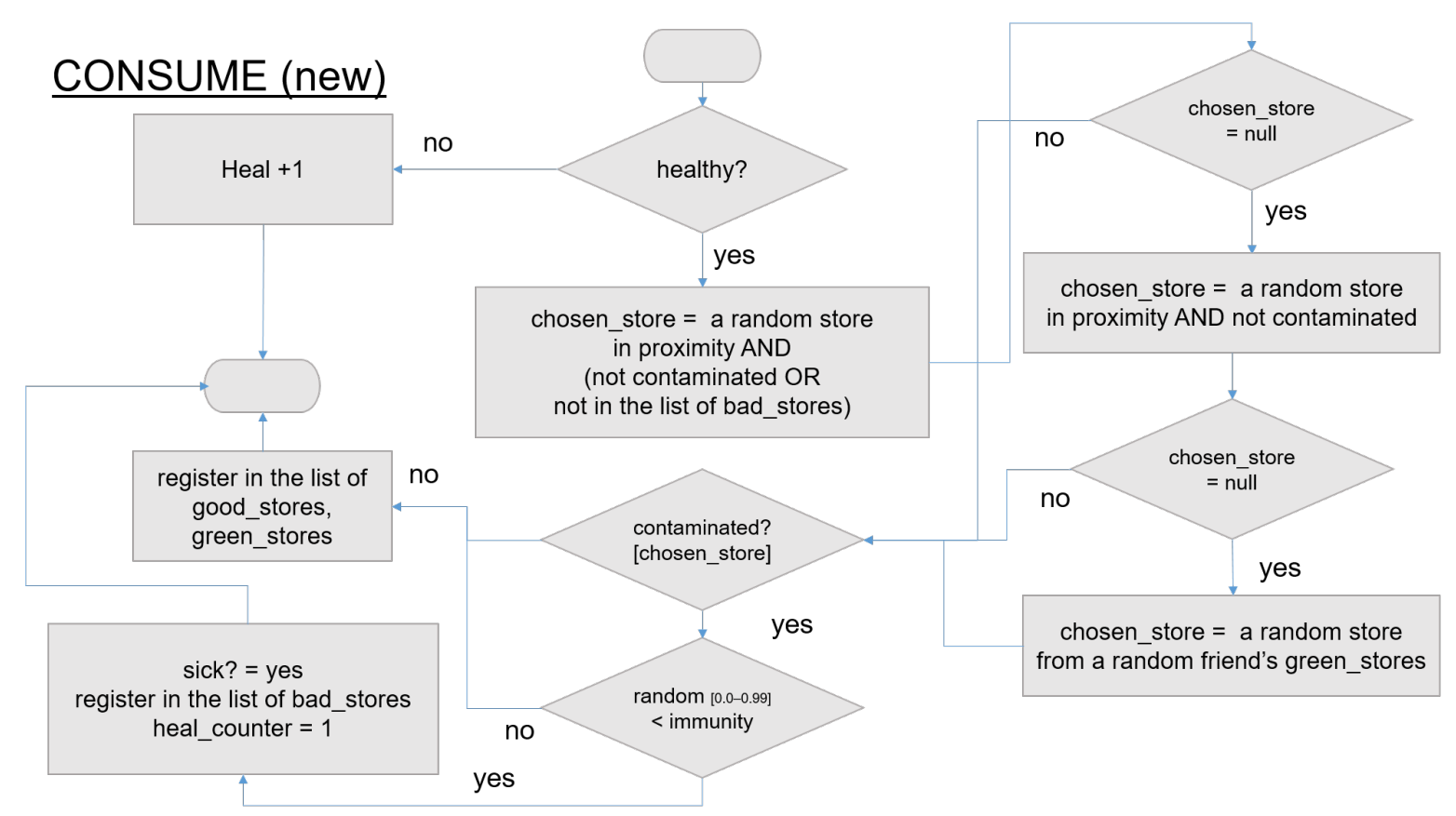

Figure 8. Proposed model of Food Safety Inspections. Process of Food Consumption by Consumers with social networking support.

\section{Simulation and Analysis of the Results}
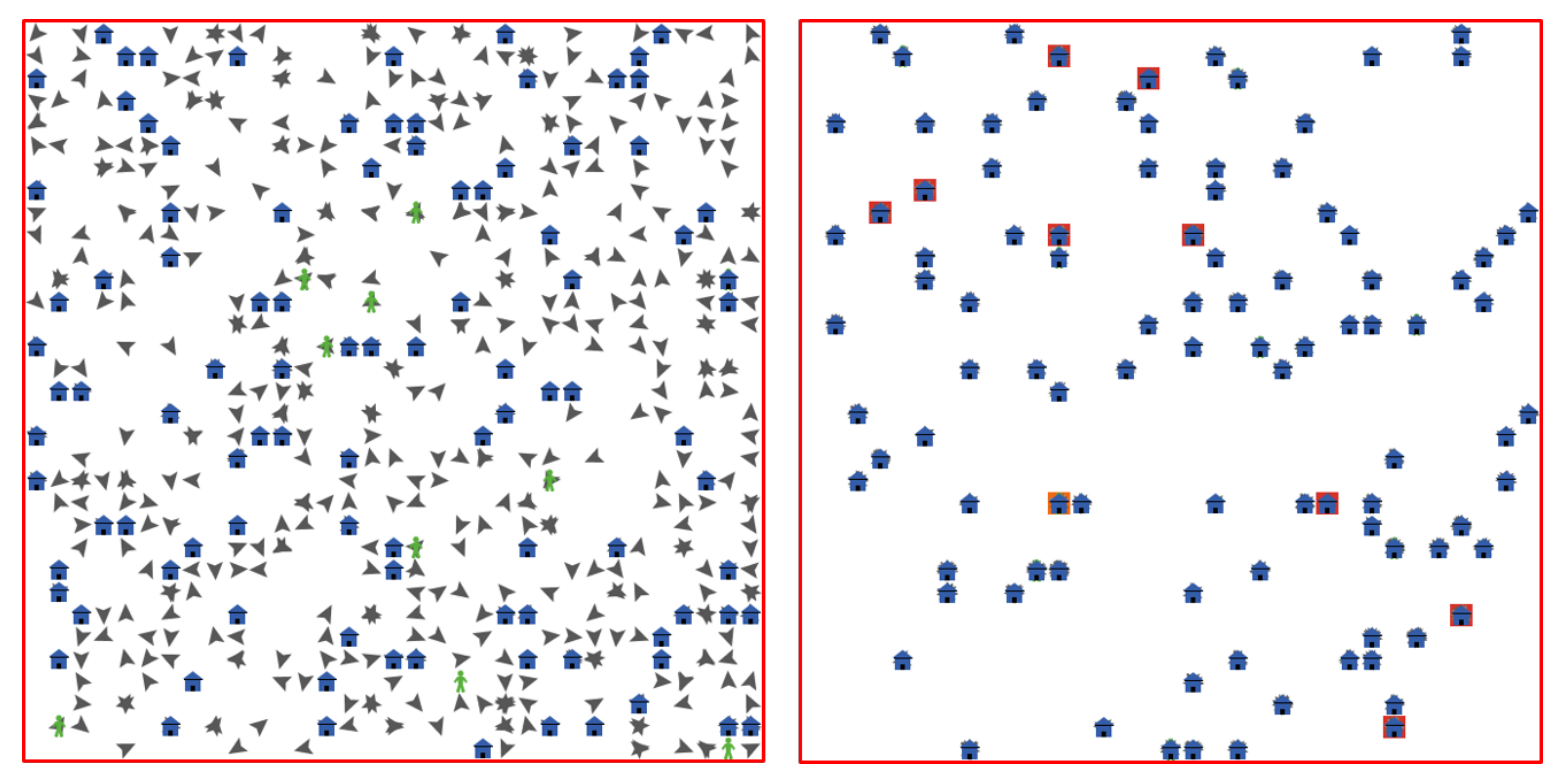

Figure 9. Case 1: Simulation space consisting of 100 stores (house shape), 10 regulators (person shape) and 500 consumers (regular agent shape). Left view shows the initialization of the simulation. Right view shows the situation at iteration 10 . The stores with red background are contaminated, the store with orange background are sterilized; 29 consumers are already sick at this stage.

The purpose of the model is to provide insights into the role of society's general sensibility towards a self-organized food safety system at the level of food consumption (consumers, stores and regulators). The model is implemented in Netlogo [27]. The simulation space consists of a cellular grid of size 33 x 33. A visualization of agents dispersion on the grid is shown in Fig. 9 for the case 1 and Fig. 10 for the case 4 . These cases implement models with increasing complexity, which are: 

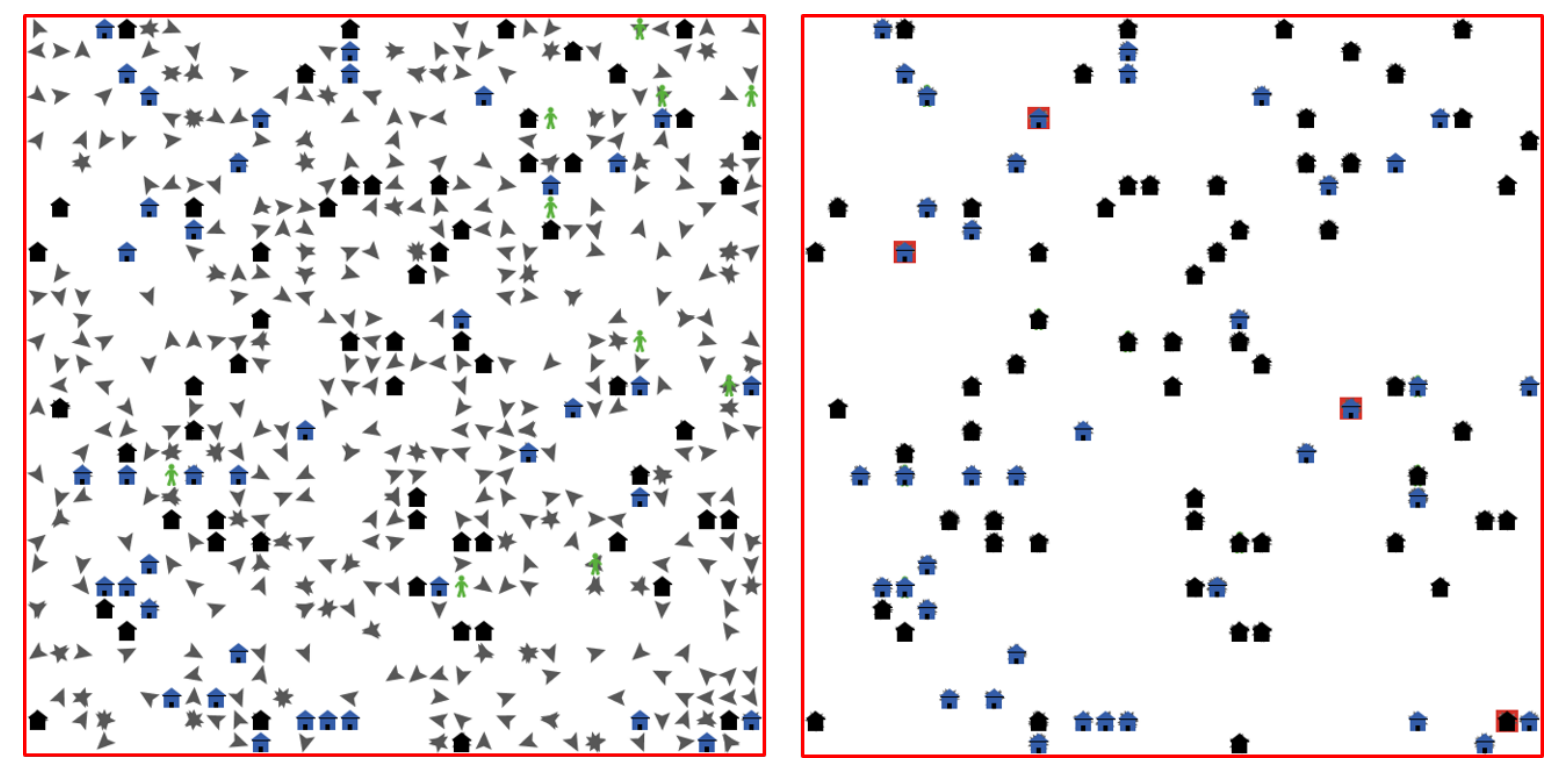

Figure 10. Case 4: Simulation space consisting of 100 stores (house shape, black stores are vigilant), 10 regulators (person shape) and 500 consumers (regular agent shape). Left view shows the initialization of the simulation. Right view shows the situation at iteration 10 . The stores with red background are contaminated; 9 consumers are already sick at this stage.

1. Case 1: Knowles's Model without Signaling.

2. Case 2: Knowles's Model with Signaling.

3. Case 3: Introduction of UPGRADE process, and the concept of progressive quality improvement or degradation of food.

4. Case 4: UPGRADE process with effect of crowd to fine tune progressive quality improvement by vigilant stores.

5. Case 5: UPGRADE process with effect of crowd to fine tune progressive quality improvement by all stores.

Each simulation is run for 100 ticks. 1000 simulations are executed for one set of simulation parameters. Simulation parameters which are constant are: stores $=100$, regulators $=10$, consumers $=$ 1000 , connectivity index $=0.5$, local connections $=80 \%$.

A sequence diagram depicting the flow of simulation is shown in Fig. 11. The Simulator is responsible to start a run. Then one of the randomly selected store performed the process of spreading, followed by (optional) signaling by five stores. Then, all consumers follow consume and heal (only those who are sick). At the end, regulators perform test of stores.

All cases from case 3 to 5 do not use signaling and perform upgrade. A sequence diagram depicting the flow of simulation in that is shown in Fig. 12.

Case 1 is presumably the worst-case and Case 2 the best-case. However, even case 2 does not provide any mechanism of fair distribution of the consumers due to lack of vigilance from stores. Case 3 introduces mechanism of progressive improvement and degradation of quality (by stores). Built on case 3, Case 4 introduces the concept of vigilant stores. Case 5 provides a hypothetically enthusiastic scenario, in which all the stores are vigilant. So, from case 3 to 5 , case 5 is presumably the best one.

The following parameters are user for the analysis:

- Sick Consumers: The number of consumers who are sick at each iteration.

- Contaminated Stores: The number of stores contaminated at each iteration.

- Sterilized Stores: The number of stores sterilized at each iteration.

- Stores Usage: Average standard deviation of stores usage, an average value of the whole simulation. 


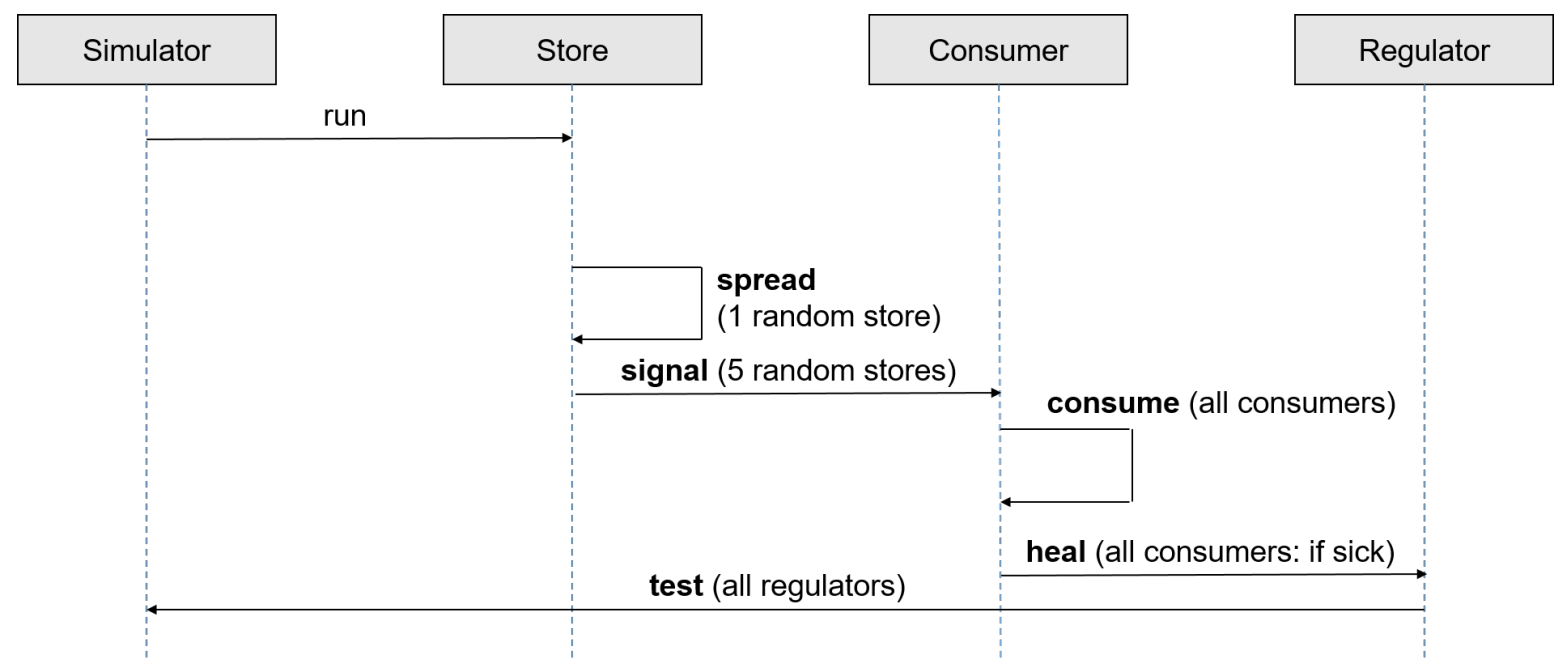

Figure 11. Sequence Diagram of Simulation Flow of Knowles model.

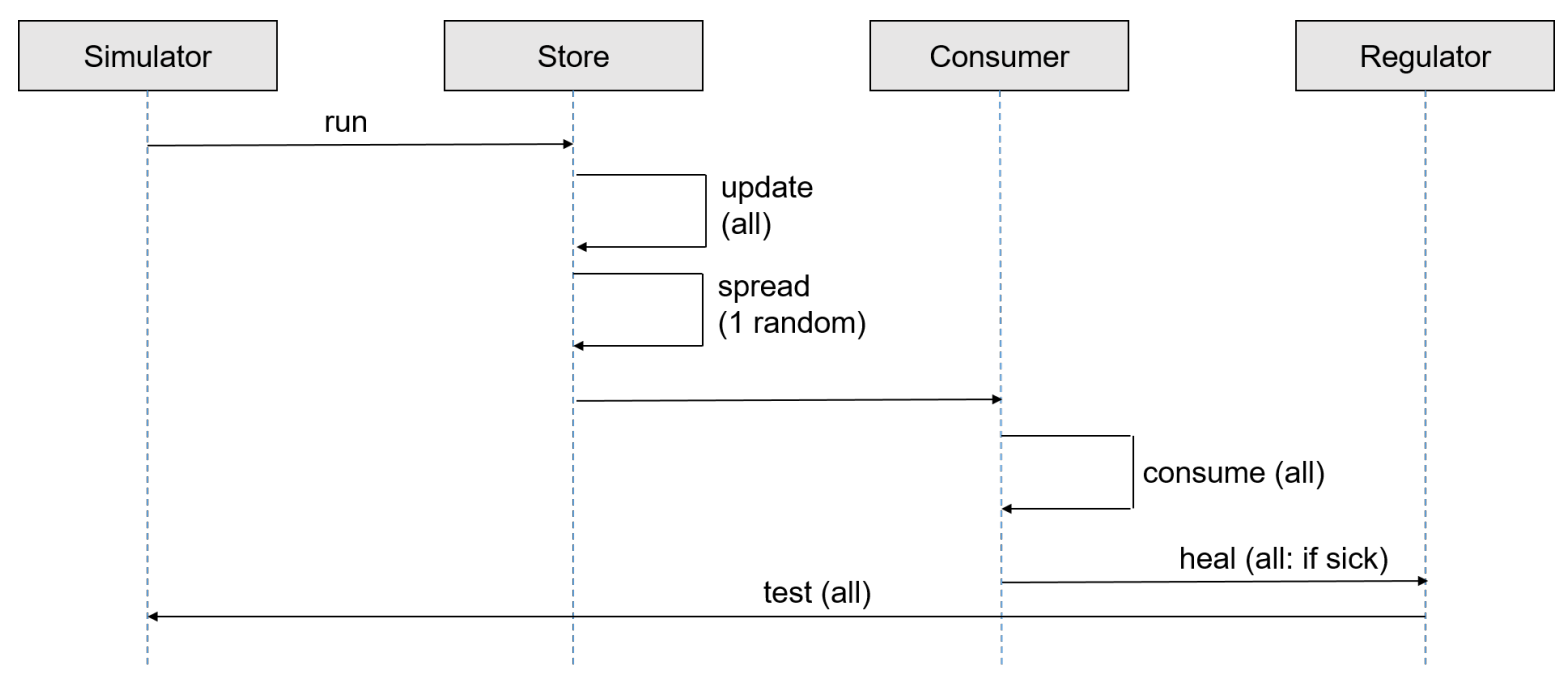

Figure 12. Sequence Diagram of Simulation Flow of our model using UPDATE and without signaling.

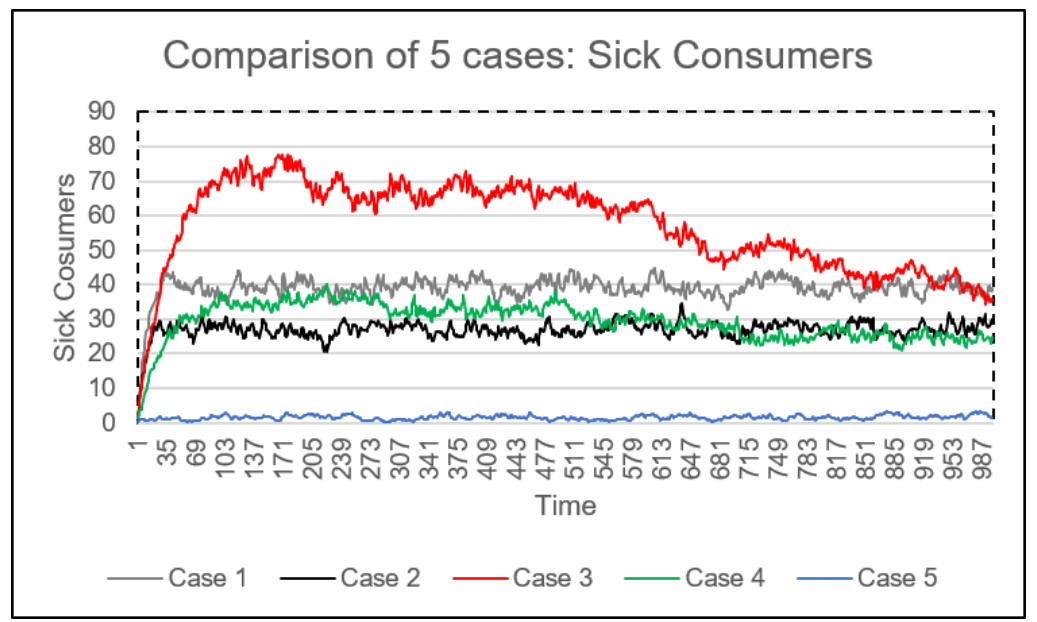

Figure 13. Simulation Results: Time Series of Sick Consumers, an average of 100 simulation runs.

Our assumption about sick consumers and case 5 to be the best case between case 3 to 5 turn out to be true. However, case 5 also outperforms case 2 . The reason is that in case 2, signaling alone 


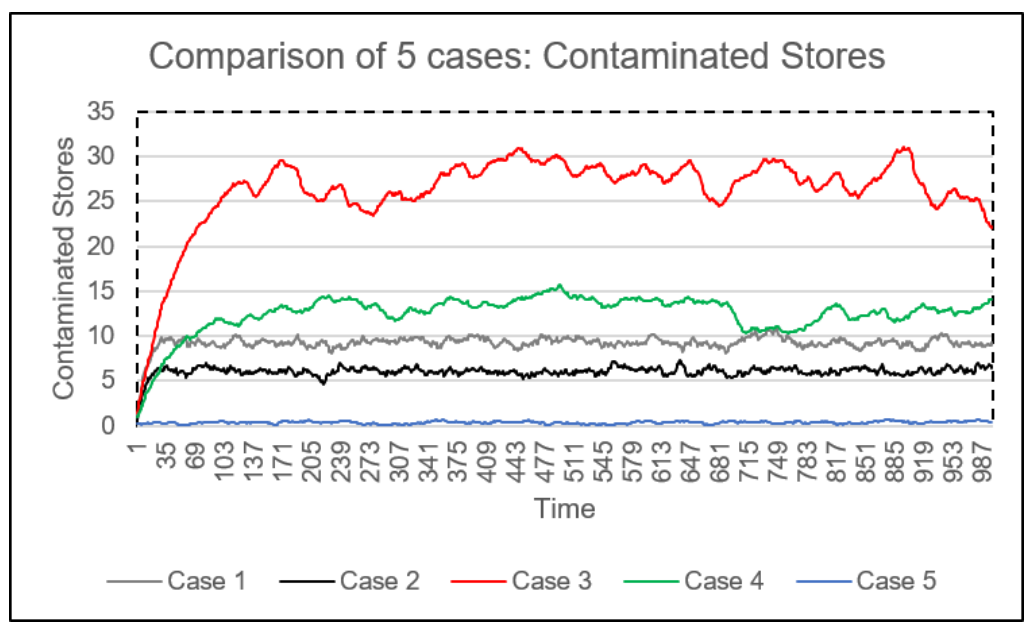

Figure 14. Simulation Results: Time Series of Contaminated Stores, an average of 100 simulation runs.

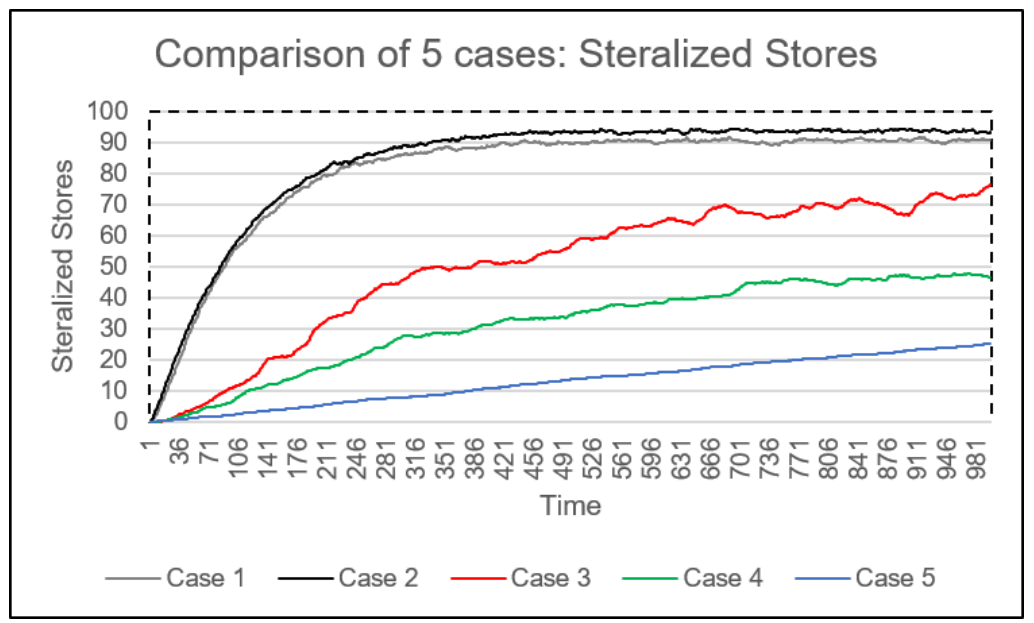

Figure 15. Simulation Results: Time Series of Sterilized Stores, an average of 100 simulation runs.

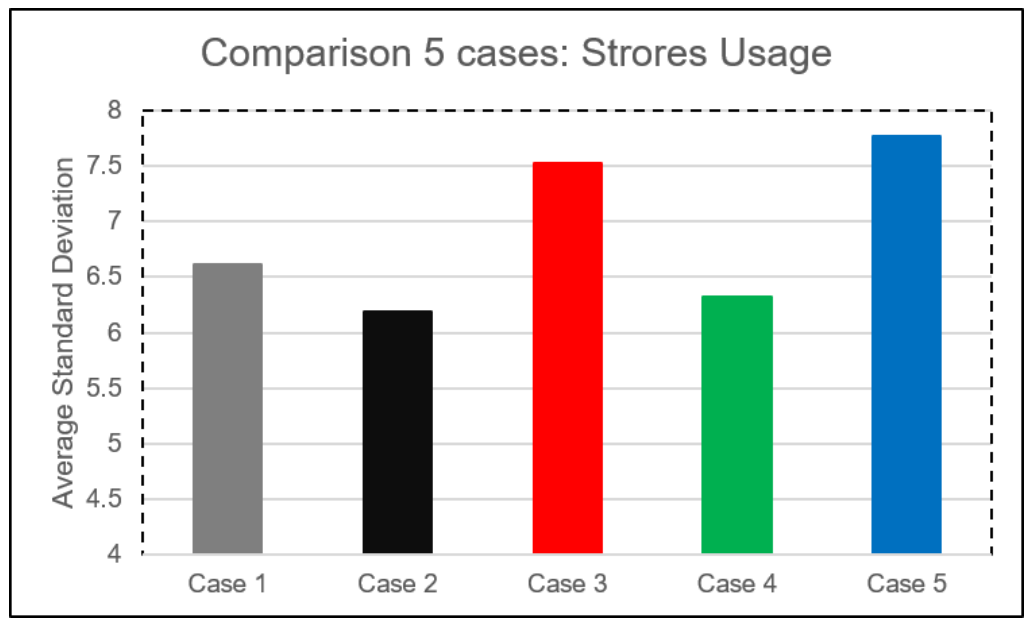

Figure 16. Simulation Results: Time Series of Stores Usage, an average standard deviation of 100 simulation runs.

does not guarantee a regulator in the proximity which could sterilize the store quickly. Whereas, in case 5, the vigilance of (all) stores just sensing a decline in the count of the consumer guarantee a 
self-correction mechanism which prevent many stores losing a substantial portion of their customers. Hence, at least for these settings of the simulation, we can conclude that an active society has capability of self-organizing without any regulatory compulsions. These results are depicted in the comparison graph shown in Fig. 13.

Also from Fig. 13, it is clear that case 3 is even worse than case 1. The reason is that progressive improvement and degradation in the quality imposes a further restriction on the contaminated stores delaying their status change from contaminated to sterilized. This fact is also evident from the graph shown in Fig. 14. All other cases are comparable with the graph shown in Fig. 13.

The graph shown in Fig. 15 depicts the comparable trends in cases 3 to 5; the more the contaminated stores are the more these become sterilized. However, case 1 and 2 have higher values than even these 3 cases, and in terms of contaminated store (Fig. 14), this is not comparable. Again the reason is the restriction imposed by progressive quality update, which inhibits the stores an abrupt status change from contaminated to sterilized.

Lastly, the fairness in stores usage is represented by average standard deviation of consumers presence at the stores. As shown in the graph in Fig. 16, the highest value comes against case 5. The standard deviation is stores usage represents the fairness in consumers presence in the stores. This means that the hypothesis that "more vigilance in correction measures ensures a large fraction of interested population available as compared to indifferent attitude" is verified. This may lead to increase in dependability and robustness of the system. However, this hypothesis not true for case 4, which turns out be the least. This means that the hypothesis should be rephrased as: "more vigilance in correction measures ensures a large fraction of interested population available as compared to indifferent attitude, provided that majority of the service providers are vigilant and sensitive to implications of "the wisdom of the crowds".

Next, we extended case 5 to implement social networking. In this model, we have used exactly the same settings as before. We have taken Case 5 as Case 5A now, and Case 5B, when case 5 is having no wondering mechanism. Case $5 \mathrm{C}$ is then the case which utilizes the friends network if no store is available in the proximity of a consumer. Naturally, we then have an additional parameter which is used to show number of consumers not able to get a store even when they required it. We represent this parameter as consumers with no store available.

The basic purpose of this extension was to decrease the number of consumers which are not able to find a store in their proximity and take help from their friends. This is successfully achieved when we compare the three cases. Case $5 \mathrm{~B}$ is the worst case. This is understandable due to the lack of wandering mechanism. Even with wandering, we have substantial number of consumers not able to find a healthy store. However, the new model proposed, ensures a real low value of number of consumers not able to find a healthy store through out the simulation time. These results are depicted in Figure 17. The other results are quite similar to what we have discussed before.

\section{Conclusion}

An agent-based model of food safety management is presented in the paper. The model extends a simple model of food safety [1] involving consumers, regulators and stores. The simulation results revealed that more vigilance in correction measures taken by the stores ensures a large fraction of consumers ending up having good quality food. Another interesting finding is the self-organizing behavior of the population. It is evidenced that an active society has a capability to self-organize even in the absence of any regulatory compulsion (a brief description already published very recently [26]). The self-organization can further extend its functional scope if we include information sharing through social networking. The implications of these findings are enormous. System components taking a self-organized corrective action resist against system going towards a highly skewed distribution, thus, improving its stability. 


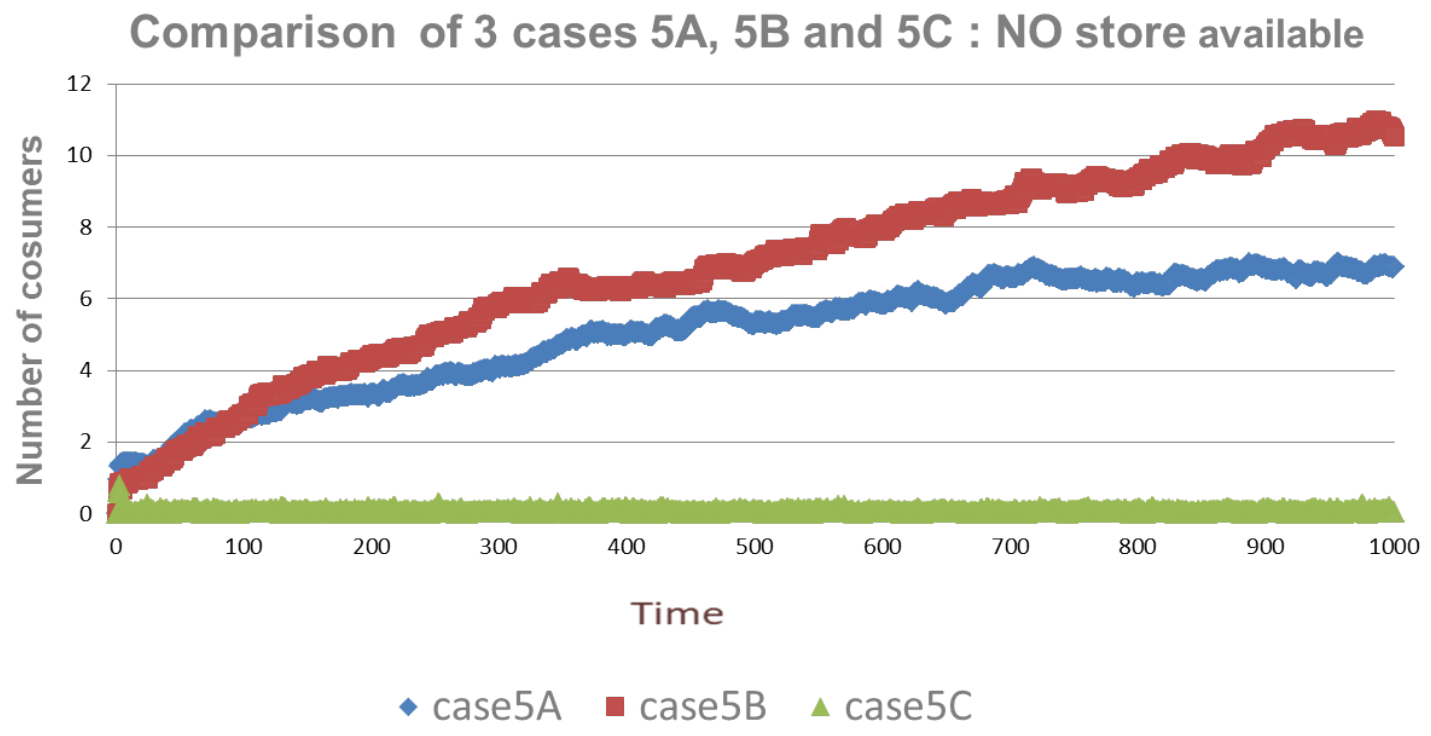

Figure 17. Simulation Results: Comparison of 3 cases (5A, 5B, and 5C). Time series of

\section{References}

1. McPhee-Knowles, S. Growing Food Safety from the Bottom Up: An Agent-Based Model of Food Safety Inspections. Journal of Artificial Societies and Social Simulation 2015, 18, 9.

2. Marks, A.B. A New Governance Recipe for Food Safety Regulation. Loy. U. Chi. LJ 2015, 47, 907.

3. Kim, R.; others. Food risk management quality (FRMQ) of government and the private firms: Consumers' perspectives in China and Korea. International Food Research Journal 2013, 20, 1503-9.

4. Borrusso, P.; Quinlan, J.J. Development and piloting of a food safety audit tool for the domestic environment. Foods 2013, 2, 572-584.

5. Unnevehr, L.; Grace, D. Aflatoxins: Finding solutions for improved food safety; Vol. 20, Intl Food Policy Res Inst, 2013.

6. Birk-Urovitz, E. The 2008 Canadian listeriosis outbreak: a result of knowledge ignored. McMaster University Journal of Medicine 2011, 8, 65-67.

7. Hoag, M.A.; Porter, C.; Uppala, P.P.; Dyjack, D.T. A risk-based food inspection program. Journal of environmental health 2007, 69, 33.

8. Thanh, T.N.C. Food safety behavior, attitudes and practices of street food vendors and consumers in Vietnam 2015.

9. Van Kleef, E.; Houghton, J.; Krystallis, A.; Pfenning, U.; Rowe, G.; Van Dijk, H.; Van der Lans, I.; Frewer, L.J. Consumer evaluations of food risk management quality in Europe. Risk Analysis 2007, 27, 1565-1580.

10. Kher, S.V.; De Jonge, J.; Wentholt, M.T.; Deliza, R.; de Andrade, J.C.; Cnossen, H.J.; Luijckx, N.B.L.; Frewer, L.J. Consumer perceptions of risks of chemical and microbiological contaminants associated with food chains: a cross-national study. International Journal of Consumer Studies 2013, 37, 73-83.

11. Bredahl, L. Determinants of consumer attitudes and purchase intentions with regard to genetically modified food-results of a cross-national survey. Journal of consumer policy 2001, 24, 23-61.

12. Lazer, D.; Pentland, A.S.; Adamic, L.; Aral, S.; Barabasi, A.L.; Brewer, D.; Christakis, N.; Contractor, N.; Fowler, J.; Gutmann, M.; others. Life in the network: the coming age of computational social science. Science (New York, NY) 2009, 323, 721.

13. Bonabeau, E. Agent-based modeling: Methods and techniques for simulating human systems. Proceedings of the National Academy of Sciences 2002, 99, 7280-7287.

14. Utomo, D.S.; Onggo, B.S.; Eldridge, S. Applications of agent-based modelling and simulation in the agri-food supply chains. European Journal of Operational Research 2017.

15. Surowiecki, J. The wisdom of crowds; Anchor, 2005. 
16. Bozkurt, I.; Padilla, J.J. On the Epistemological, Ontological, Teleological and Methodological Currents in Modeling and Simulation: An Overview. International Journal of Agent Technologies and Systems (IJATS) 2013, 5, 1-18.

17. Bleda, M.; Shackley, S. Simulation modelling as a theory building tool: the formation of risk perceptions. Journal of Artificial Societies and Social Simulation 2012, 15, 2.

18. Zia, K.; Saini, D.K.; Farooq, U.; Ferscha, A. Web of Social Things: Socially-Influenced Interaction Modeling. Proceedings of the 15th International Conference on Advances in Mobile Computing \& Multimedia. ACM, 2017, pp. 123-130.

19. Zafar, M.; Zia, K.; Saini, D.K.; Muhammad, A.; Ferscha, A. Modeling human factors influencing herding during evacuation. International Journal of Pervasive Computing and Communications 2017, 13, 211-234.

20. Zia, K.; Ferscha, A.; Din, A.; Shahzad, K.; Majeed, A. Impact of ICT-mediated collective awareness on urban mobility. Complex Adaptive Systems Modeling 2016, 4, 10.

21. Zia, K.; Shaheen, M.; Farooq, U.; Nazir, S. Conditions of Depleting Offender Behavior in Volunteering Dilemma: An Agent-Based Simulation Study. International Conference on Simulation of Adaptive Behavior. Springer, 2016, pp. 352-363.

22. Ge, H.; Nolan, J.; Gray, R.; Goetz, S.; Han, Y. Supply chain complexity and risk mitigation-A hybrid optimization-simulation model. International Journal of Production Economics 2016, 179, 228-238.

23. Utomo, D.S.; Onggo, B.S.; Eldridge, S. Applications of agent-based modelling and simulation in the agri-food supply chains. European Journal of Operational Research 2017.

24. Verwaart, T.; Valeeva, N.I. An agent-based model of food safety practices adoption. In Emergent results of artificial economics; Springer, 2011; pp. 103-114.

25. Talley, J.B. Modeling individual consumer food contamination progression with interventions. PhD thesis, North Carolina Agricultural and Technical State University, 2016.

26. Zia, K.; AlBadi, K.; Saini, D.K.; Muhammad, A. Conditions leading towards a more robust food safety system: The results of an agent-based social simulation. 2018 IEEE 9th International Conference on Dependable Systems, Services and Technologies (DESSERT). IEEE, 2018.

27. Tisue, S.; Wilensky, U. Netlogo: A simple environment for modeling complexity. International conference on complex systems. Boston, MA, 2004, Vol. 21, pp. 16-21. 